\title{
Linguistic focus and good-enough representations: An application of the change-detection paradigm
}

\author{
PATRICK STURT and ANTHONY J. SANFORD \\ University of Glasgow, Glasgow, Scotland \\ ANDREW STEWART \\ University of Manchester, Manchester, England \\ and \\ EUGENE DAWYDIAK \\ University of Glasgow, Glasgow, Scotland
}

\begin{abstract}
A number of lines of study suggest that word meanings are not always fully exploited in comprehension. In two experiments, we used a text-change paradigm to study depth of semantic processing during reading. Participants were instructed to detect words that changed across two consecutive presentations of short texts. The results suggest that the full details of word meanings are not always incorporated into the interpretation and that the degree of semantic detail in the representation is a function of linguistic focus. The results provide evidence for the idea that representations are only good enough for the purpose at hand (Ferreira, Bailey, \& Ferraro, 2002).
\end{abstract}

Recent work on discourse processing reveals growing evidence that discourse representations may vary in the detail they encode and may sometimes be underspecified (Ferreira, Bailey, \& Ferraro, 2002; Sanford, 2002; Sanford \& Sturt, 2002). Ferreira et al. claim that we represent language input at a degree of specification that is sufficient only for the situation that we are in-what they call good enough representations. The present article aims to explore a factor that might influence the degree of specification with which the meaning of a word is represented. We test the hypothesis that the degree of specification is influenced by information structure: A word's meaning is represented in more detail when it is focused in a sentence's information structure than when it is not. This is analogous to claims made by researchers in visual cognition that visual memory is selective, and that information that is "important" in some sense is represented in more detail than information that is not (e.g., Simons \& Levin, 1997). Our experimental method is related to the change-detection technique used in visual cognition research (e.g., Simons \& Levin, 1997), except that in our case, the stimuli are short texts rather than visual scenes. Participants are required to read the short texts

This research was supported by Economic and Social Research Council Grants R000223622 and R000239888. We thank Muriel Walker for running Experiment 1, and Angela Lynn for working on the materials and running Experiment 2. We also thank Fernanda Ferreira and Keith Rayner for very useful comments on earlier versions of this article. Correspondence concerning this article should be addressed to P. Sturt, Department of Psychology, University of Glasgow, 58 Hillhead Street, Glasgow G12 8QB, Scotland, UK (e-mail: patrick@psy.gla.ac.uk). twice, and to detect whether or not a word has changed from the first presentation to the second.

One important demonstration that word meaning is sometimes underutilized comes from the study of semantic illusions. With the Moses illusion (Erickson \& Matteson, 1981), many people consider (1) as true, even though Moses did not put animals on the Ark:

Moses put two of each sort of animal on the Ark.

True or false?

Failures to detect the anomaly in (1) are genuine and have been attributed to a failure to retrieve the basic information that it was Noah, not Moses, who did this. The Moses illusion has typically been treated within a memoryretrieval framework (e.g., Reder, 1982, 1987), but other failures to detect anomalies reflect more clearly a failure to utilize (dictionary style) word meaning rather than aspects of encyclopedic knowledge. Thus Barton and Sanford (1993) tested variants of the following:

After an air crash on the border of France and Spain, where should the survivors be buried?

The proportion of people who detected the anomaly depended on a variety of factors, including the general scenario. So, when bicycle crash was substituted for air crash, the proportion of detections increased dramatically. Barton and Sanford (1993) argued that survivors is less relevant in the context of bicycle crashes than air crashes, and that the amount of detail with which a word's meaning is represented in the discourse representation is a function of its fit to a context: Semantic detail increases as fit decreases. 
Such illusions show that word meaning is not always fully specified in the discourse representation. However, a major question is whether there are any general principles governing the extent to which a word's meaning will be specified. One potentially important factor, explored here, is linguistic focus.

Rooth $(1992,1995)$ defines linguistic focus in terms of sets of alternative interpretations. A simple way to illustrate this is to consider declarative sentences like (4) as answers to questions like (3A-3C):

Who introduced Bill to Sue?

What did John do?

What happened?

John introduced Bill to Sue.

If (4) is an answer to (3A), linguistic focus in (4) is on John. Intuitively, the proposition expressed by (4) is being picked out as one of a set of alternative propositions of the form [ $x$ introduced Bill to Sue] (where $x$ ranges over individuals); in this case, (4) picks out the proposition that correctly answers the question asked in (3A).

"Narrow focus" effects like this can be contrasted with "broad focus," where focus is placed on a larger linguistic domain; for example, if (4) is the answer to (3B), focus is on the predicate expressed by the verb phrase introduced Bill to Sue, whereas if (4) is an answer to (3C), focus is on the proposition expressed by the whole sentence.

In English, there are various ways of assigning focus to different elements in a sentence, besides putting them in the context of questions such as (3A-3C). In spoken language, this can be done with pitch accents, while syntactic devices like cleft constructions provide a domainneutral mechanism. Compare (5) and (6):

Moses put two of each kind of animal on the Ark. True or false?

It was Moses who put two of each kind of animal on the Ark. True or false?

In the default interpretation of (6), focus is on Moses because of the it-cleft construction. Thus, (6) is naturally interpreted as the answer to the question Who put two of each kind of animal on the Ark? In contrast, in the absence of contextual or intonational cues, (5) is more naturally interpreted with broad focus-for example, as an answer to the question What happened? Using just these examples, Bredart and Modolo (1988; Bredart \& Docquier, 1989) showed that (6) caused higher detection rates of the Moses illusion than (5), supporting the idea that focus increases the extent, or impact, of semantic analysis.

Rather than relying on failures to notice anomalies, the present study exploits failures to detect changes in consecutive presentations of a text. In visual perception, much use has been made of the change-blindness paradigm (e.g., Hollingworth \& Henderson, 2002; Holling- worth, Schrock, \& Henderson, 2001; Simons \& Levin, 1997). Change blindness, or the failure to notice changes in consecutive presentations of complex visual scenes, has been attributed to failure to attend to certain aspects of the scene, or to impoverished representations in visual memory (Rensink, 2000; Rensink, O'Regan, \& Clark, 1997). The change-detection technique can be used to explore selective attention in visual processing, since factors that affect the ability to detect changes can be assumed to influence the allocation of attention resources. In the work presented here, we examined failures in the detection of changes in text as a way of determining the factors that modulate attention during linguistic processing. The results can be seen as informative about the level of semantic detail with which the changed element is encoded in the discourse representation, in a manner analogous to change blindness in vision.

The change-detection technique is related to certain sentence memory tasks. In a classic study, Sachs (1967) had participants listen to short passages and subsequently tested whether the participants thought a test sentence had appeared in the passage. The test sentences were presented either immediately after the passage or at some delay. The test sentences involved semantic changes, or syntactic changes, or no change at all. Sachs found that participants were adept at detecting semantic changes, but performance decreased markedly over time for syntactic changes, where the meaning of the sentence did not differ markedly between the two sentence forms. These results were interpreted as showing that the surface form of a sentence is retained in memory only for the time necessary for the comprehension processes to be carried out and is not stored with the sentence's meaning. Caveats to this argument include a body of evidence showing that memory for the surface structure of utterances is retained when the participants are recalling highly interactional content (e.g., Bates, Masling, \& Kintsch, 1978). The change-detection technique described in the present article is designed to look at immediate recall. We argue that whether or not a semantic change is detected should depend on the level of detail with which the meaning of the word is represented in the first place, and on whether the changed word is similar or dissimilar in meaning to the original word. The change-detection technique is also related to other tasks used in psycholinguistic research, including the sentence-matching paradigm (Forster \& Stevenson, 1987; Murray \& Rowan, 1997), with which researchers have studied other aspects of syntactic and semantic processing. In a similar task, Raney and Rayner (1995) had participants read a passage twice, with a word in that passage changing in some conditions. Raney and Rayner were investigating eye movements, however, not the detection of the change.

In the two experiments described below, we used a textchange procedure to investigate how failure to detect changes may be related to focus and semantic variables. 


\section{EXPERIMENT 1}

In the first experiment, focus was manipulated using cleft constructions, as in Bredart and Modolo (1988). Consider the following:

[Focus on the cider]

Everyone had a good time at the pub. A group of

friends had met up there for a stag night. What

Jamie really liked was the cider, apparently.

In (7A), the pseudocleft construction leads to focus on the cider. The preferred interpretation is one in which cider is implicitly contrasted to a set of other things that Jamie might also have liked. Clearly, this noun phrase is highlighted in the interpretation, and we predict that changes to the word cider should be relatively well noticed. Compare this with the following:

\section{[Focus on Jamie]}

Everyone had a good time at the pub. A group of

friends had met up there for a stag night. It was

Jamie who really liked the cider, apparently.

Here, the use of the cleft construction puts Jamie into sentence focus. The preferred interpretation is one in which Jamie is contrasted to other individuals who may have liked the cider. Because emphasis is now on an alternative noun phrase, we predict that changes to the word cider should be less readily noticed in (7B) than in (7A).

Detection should also be a function of the kind of changes made to the words. According to our hypothesis, the degree of specification with which a word's meaning is represented should depend on focus. We suggest that word meaning can be represented at different levels of granularity, or specification (Hobbs, 1985). Thus, even though in a text the description might be cider, the discourse representation may under some circumstances encode a superordinate category such as drink, reflecting what Hobbs called a coarser level of granularity. We propose that linguistic devices signaling focus, including cleft constructions and contextual cues, affect the specification with which word meanings are represented. Consider (7B). If the unfocused word cider is represented with a superordinate word meaning in the discourse representation, then a change to a related word such as beer should be relatively easy to miss, because both meanings are members of the basic category drink. On the other hand, a much more detectable change would involve shifting from cider to an entity outside this category, such as music. However, in (7A), cider is in focus, and we hypothesize that readers represent the meaning at a finer level of granularity. This should increase the detection rates even for changes involving related meanings, such as the change from cider to beer.

\section{Method}

\section{Participants}

Forty participants from the University of Glasgow community took part in the experiment. All were native speakers of English.

\section{Experimental Items and Design}

There were 28 experimental materials, similar to (7A) and (7B) above. Focus was manipulated using $i t$-cleft and pseudocleft sentences. The changed noun was always the head of a noun phrase that was put in focus by the pseudocleft (e.g., "What Jamie really enjoyed was the cider apparently"), and this critical noun changed either to a word with a related meaning (e.g., cider to beer) or to a word with an unrelated meaning (e.g., cider to music). Changes in the related meaning conditions always involved words that shared a basic level of categorization, and changes in the unrelated meaning conditions always involved words outside this category (e.g., cider to music).

In what follows, we will call the pseudocleft sentences, like (7A), focused, because the critical (changed) noun is in focus, and we will call the $i$ t-cleft sentences, like (7B), unfocused, because the critical noun is not in focus.

Experimental materials contained three sentences, and the sentence in which the critical change occurred was always either the second or the third. The unfocused and focused conditions differed only in the syntactic structure of the critical sentence.

The items were divided into four lists, with an equal number (28) of items per list. Each list contained one of the four possible versions of each item, but overall contained an equal number of all conditions. To these were added 48 filler items ( 24 were from an unrelated experiment) which included either large or small semantic changes to verbs. Another 12 fillers had no change at all, and a further 12 fillers had changes in various physical locations in the text, involving words of different parts of speech. The fillers used a variety of constructions, including some cleft constructions. Presentation was in a random order.

\section{Procedure}

The texts were presented on a Macintosh computer with PsyScope (Cohen, MacWhinney, Flatt, \& Provost, 1993) software. Trials began with an asterisk marking the position of the first character of text. The participant pressed a button to begin each trial. The timing of the first display was varied between participants, as part of our initial exploration of the experimental technique; for half the participants, the first display appeared for $8 \mathrm{sec}$, and the other half of the participants read the first display at their own pace, pressing a button when they had finished. This between-subjects factor was involved in no main effects or interactions in subsequent analysis and will not be discussed further. The analyses reported below collapse over this factor. After the initial display, the text was replaced by a gray screen for $500 \mathrm{msec}$, followed by the second display of the text. The participants read through this when it appeared and were required to press the button again when they had finished reading. The second display appeared for a maximum of $10 \mathrm{sec}$. Participants were to tell the experimenter whether or not they had detected a change, and if so, what that change was. The response was counted as correct if the changed word was correctly identified. The reading instructions stressed making a single read-through at each presentation. Participants were further told simply to read for meaning, and that there would be changes to a single word on some trials.

\section{Results and Discussion}

Mean detection rates and standard errors for the four conditions are given in Figure 1. Analyses of variance (ANOVAs) were computed on the mean percentages for each participant $\left(F_{1}\right)$ and each item $\left(F_{2}\right)$, treating semantic change (change to a related word vs. an unrelated word) and focus (critical noun focused vs. unfocused) as the within-subjects and within-items factors. The results of these analyses are shown in Table 1.

The table shows that both focus and semantic distance reliably affected detection of change. Although the inter- 
Experiment 1

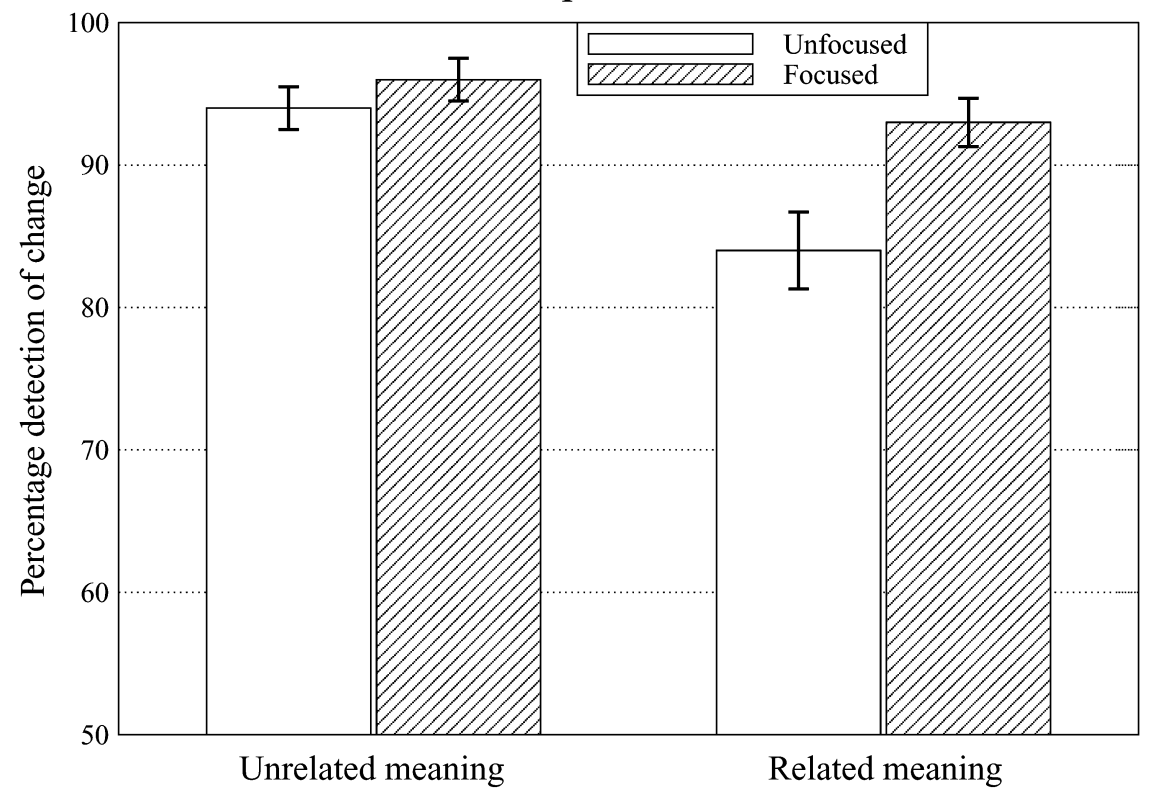

Figure 1. Detection as a function of condition for Experiment 1 (means and standard errors).

action between the two factors was significant only on the analysis by items, follow-up analyses tested the a priori prediction that changes to related words should be noticed more often when the word was in focus than when it was out of focus, but that focus made no difference when the change was to a word with unrelated meaning. This was indeed the case (see simple effects, Table 1).

We noticed that the overall detection rates, even for the related meaning conditions, were fairly high. One possible explanation is that the use of the rather marked cleft constructions might have caused readers to allocate more attention to form than would normally be the case. This would naturally elevate detection rates, particularly for the related meaning conditions, where word form is particularly discriminative.

\section{EXPERIMENT 2}

This experiment sought to replicate the results of Experiment 1, using a different focus manipulation, and without using marked syntactic forms such as clefts.
Here, focus was manipulated through a prior context sentence:

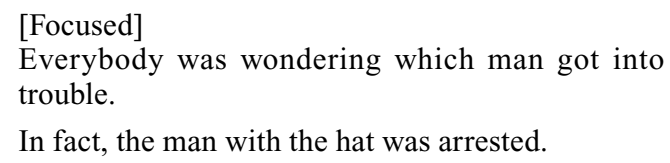

Here, the first sentence includes an embedded question asking, "Which man got into trouble?" It is thus natural to interpret the second sentence with narrow focus on the prepositional phrase with the hat, because the property of having a hat identifies a particular man from a set of implicit alternatives, leading to an answer to the embedded question in the first sentence. So we predict that changing the word hat to something else would tend to be noticed. Contrast this with the following:

\section{[Unfocused]}

Everybody was wondering what was going on that night.

In fact, the man with the hat was arrested.

Table 1

Results of Statistical Analysis for Experiment 1

\begin{tabular}{|c|c|c|}
\hline Effect & $F_{1}(1,39)=$ & $F_{2}(1,27)=$ \\
\hline Main effect: Semantic distance & $12.20 *$ & $8.35^{*}$ \\
\hline Main effect: Focus & $15.79 *$ & $9.00 *$ \\
\hline Interaction: Focus $\times$ distance & 2.73 (n.s.) & $4.57 *$ \\
\hline Simple effect: Focus effect for semantically unrelated & $<1$ (n.s.) & 1.50 (n.s.) \\
\hline Simple effect: Focus effect for semantically related & $10.80^{*}$ & $8.49 *$ \\
\hline
\end{tabular}

$* p<.05$. 
Here, the second sentence is most naturally interpreted with broad focus on the proposition expressed by the whole sentence, in comparison with the set of other propositions describing other things that might have happened. The attribute of having a hat is much less relevant here, since there is no necessity to identify a particular man, and hence little need to use information that might enable that man to be contrasted with other men. We predict that changes involving the word hat in (8B) would be less likely to be noticed than in (8A).

As in Experiment 1, semantic distance was manipulated as well as focus, so that, for example, in (8B), the word hat could change either to a related word of the same basic category (cap) or to an unrelated word ( $\mathrm{dog}$ ). Again, we predicted that changes to related words would be noticed more under focused conditions.

\section{Method}

\section{Participants}

Twenty-four native speakers of English from the University of Glasgow community participated in the experiment.

\section{Design and Materials}

There were 24 experimental materials, constructed on the model of (8A) and (8B). Experimental materials contained three sentences, and the sentence on which the critical change occurred was always the second (in filler sentences, changes occurred in other locations). The unfocused and focused conditions differed only in the content of the first sentences [see (8A) and (8B)]. The unfocused conditions used a variety of structures in the first sentence, but never involved an embedded question that was answered by the noun-plus-modifier in the second sentence. Changes always occurred inside the critical modifier (e.g., . . . with the hat . .., or with the roses) in the second sentence.
The items were divided into four lists, with an equal number (24) of items per list. Each list contained one of the four possible versions of each item, but overall contained an equal number of all conditions. To these were added 24 filler items that had no change, and a further 48 fillers of varying structures with changes covering a range of positions in all three sentences. Presentation was in random order.

\section{Procedure}

The procedure was identical to that of Experiment 1, except that the second text display did not stop after $10 \mathrm{sec}$.

\section{Results and Discussion}

The percentages of change detections under each condition are shown in Figure 2, and statistical analyses are reported in Table 2.

Changes were detected less often overall than in Experiment 1 , especially in the related meaning conditions (compare Figures 1 and 2). We attribute this to the fact that fewer marked sentence structures were used in this experiment. ${ }^{1}$

As in Experiment 1, both focus and semantic distance affected change-detection rates. Again, as in Experiment 1, there was a significant interaction, such that focus made a significant difference when the change was to a related word, but had no effect when the change was to an unrelated word (see Table 2).

\section{GENERAL DISCUSSION}

The text-change detection paradigm appears to be potentially useful for investigating the extent of processing afforded to lexical items during reading. We believe that the task is rather different from normal recognition mem-

\section{Experiment 2}

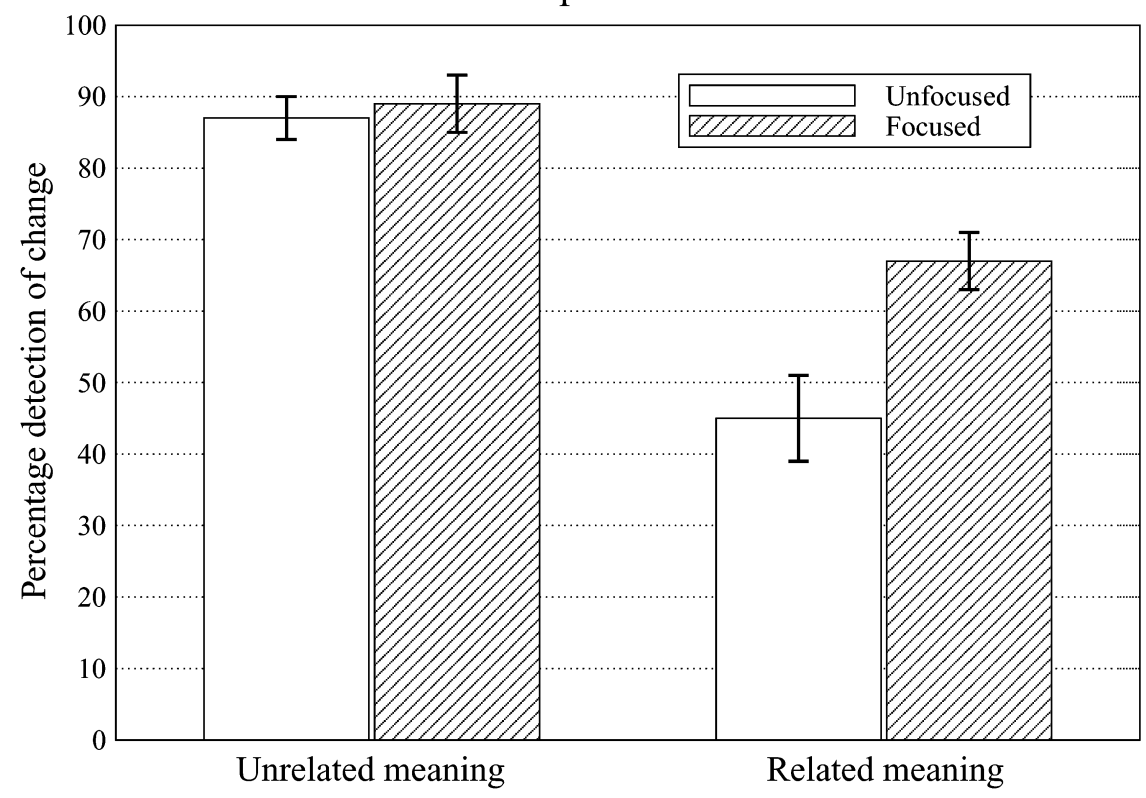

Figure 2. Detection as a function of condition for Experiment 2 (means and standard errors). 
Table 2

Results of Statistical Analysis for Experiment 2

\begin{tabular}{lcc}
\hline \multicolumn{1}{c}{ Effect } & $F_{1}(1,23)=$ & $F_{2}(1,23)=$ \\
\hline Main effect: Semantic distance & $88.22^{*}$ & $42.22^{*}$ \\
Main effect: Focus & $8.90^{*}$ & $10.30^{*}$ \\
Interaction: Focus $\times$ distance & $6.50^{*}$ & $8.58^{*}$ \\
Simple effect: Focus effect for semantically unrelated & $<1$ (n.s.) & $<1$ (n.s.) \\
Simple effect: Focus effect for semantically related & $10.99 *$ & $11.78^{*}$ \\
$* p<.05$. & &
\end{tabular}

ory tasks, which typically bring attention to bear on particular items or locations, such as first or subsequently mentioned characters (e.g., Gernsbacher, 1989). For example, in our studies the experimenters noticed that participants' wrongly proposed changes (false alarms) did not appear to involve words in any one particular physical location of the text. Moreover, the fact that we obtained an effect of focus shows that subjects were actually interpreting the sentences, not merely adopting an artificial word-monitoring strategy.

The data support the theory that focus influences the specificity of the meaning representation of content words, when focus is induced through syntax (Experiment 1) and context (Experiment 2). Thus, they offer some tangible support for Ferreira et al.'s (2002) notion of a good enough representation.

With a few exceptions (Birch \& Garnsey, 1995; Birch \& Rayner, 1997; Morris \& Folk, 1998), the possibility that focus influences lexical semantic processing has been underexplored. Birch and Garnsey examined the effect of focus using a probe-naming task. After seeing sentences like (9) and (10), participants pronounced a probe word that was related to the target word (such as gardener) or unrelated (such as clothes).

It was the farmer who would decide whether to sell the plot of land.

The house that the farmer owned was built during the depression.

The investigators expected the pronunciation of related words to be speeded in the focused case (9) because of more extensive semantic processing. However, they found the opposite, with greater facilitation in the unfocused case. This result is consistent with our suggestions. Because the word meaning corresponding to farmer is represented at a finer level of granularity in (9), the related term gardener is more easily recognized as being different. The longer naming times in (9) could thus be explained in terms of interference.

This article represents initial progress toward answering the question of what degrees of meaning specification are used during comprehension, and how this specification is modulated. One of our goals was to test the prediction that the degree of specification depends on relative prominence, as manipulated through focus, and this result was obtained. Future work will test the effect of other focus-related manipulations, such as clause subordination. And it should be possible to use the detection-change technique to answer general questions - for example, whether or not that which participants find interesting in a text influences detail of representation. It is also desirable to investigate the relation between eye movements and change detections. One question is whether focus affects the probability of initially fixating a word and how this influences detection performance. Recent work in vision has separated the influences of initial eye fixation and short-term memory on noticing changes in scenes (Hollingworth \& Henderson, 2002), showing that changes can affect processing behavior, even when participants report no change. This issue clearly requires investigation for the text-change paradigm.

\section{REFERENCES}

Barton, S. B., \& SANFord, A. J. (1993). A case study of anomaly detection: Shallow semantic processing and cohesion establishment. Memory \& Cognition, 21, 477-487.

Bates, E., MAsLING, M., \& KinTSCH, W. (1978). Recognition memory for aspects of dialogue. Journal of Experimental Psychology: Human Learning \& Memory, 4, 187-197.

BIRCH, S. L., \& GARNSEY, S. M. (1995). The effect of focus on memory for words in sentences. Journal of Memory \& Language, 34, 232267.

BIRCH, S. L., \& RAYNER, K. (1997). Linguistic focus affects eye movements during reading. Memory \& Cognition, 25, 653-660.

Bredart, S., \& Docquier, M. (1989). The Moses illusion: A follow-up on the focalization effect. Cahiers de Psychologie Cognitive/European Bulletin of Cognitive Psychology, 9, 357-362.

Bredart, S., \& Modolo, K. (1988). Moses strikes again: Focalization effects on a semantic illusion. Acta Psychologica, 67, 135-144.

Cohen, J. D., MacWhinney, B., Flatt, M., \& Provost, J. (1993). PsyScope: An interactive graphic system for designing and controlling experiments in the psychology laboratory using Macintosh computers. Behavior Research Methods, Instruments, \& Computers, 25, 257-271.

ERICKSON, T. A., \& Matteson, M. E. (1981). From words to meaning: A semantic illusion. Journal of Verbal Learning \& Verbal Behavior, 20, 540-552.

Ferreira, F., Bailey, K. G. D., \& Ferraro, V. (2002). Good enough representations in language comprehension. Current Directions in Psychological Science, 11, 11-15.

FoRSTER, K. I., \& STEVENSON, B. (1987). Sentence matching and wellformedness. Cognition, 26, 171-186.

Gernsbacher, M. A. (1989). Mechanisms that improve referential access. Cognition, 32, 99-156.

Hoвbs, J. R. (1985, August). Granularity. Paper presented at the International Joint Conference on Artificial Intelligence, Los Angeles.

Hollingworth, A., \& Henderson, J. M. (2002). Accurate visual memory for previously attended objects in natural scenes. Journal of 
Experimental Psychology: Human Perception \& Performance, 28, 113-136.

Hollingworth, A., Schrock, G., \& Henderson, J. M. (2001). Change detection in the flicker paradigm: The role of fixation position within the scene. Memory \& Cognition, 29, 296-304.

Morris, R. K., \& FoLK, J. R. (1998). Focus as a contextual priming mechanism in reading. Memory \& Cognition, 26, 1313-1322.

MurRaY, W. S., \& Rowan, M. (1997). Early, mandatory, pragmatic processing. Journal of Psycholinguistic Research, 27, 1-22.

RANEY, G. E., \& RAYNER, K. (1995). Word frequency effects and eye movements during two readings of a text. Canadian Journal of Experimental Psychology, 49, 151-172.

REDER, L. M. (1982). Plausibility judgements vs. fact retrieval: Alternative strategies for sentence verification. Psychological Review, 89, 250-280.

REDER, L. M. (1987). Strategy selection in question-answering. Cognitive Psychology, 19, 80-138.

RENSINK, R. A. (2000). The dynamic representation of scenes. Visual Cognition, 7, 17-42.

Rensink, R. A., O’REgan, J. K., \& Clark, J. J. (1997). To see or not to see: The need for attention to perceive changes in scenes. Psychological Science, 8, 368-373.
Rooth, M. (1992). A theory of focus interpretation. Natural Language Semantics, 1, 75-116.

Rooth, M. (1995). Focus. In S. Lappin (Ed.), Handbook of contemporary semantic theory (pp. 271-298). London: Blackwell.

SACHS, J. S. (1967). Recognition memory for syntactic and semantic aspects of connected discourse. Perception \& Psychophysics, 2, 437442 .

SANFORD, A. J. (2002). Context, attention and depth of processing during interpretation. Mind \& Language, 17, 199-206.

SANFord, A. J., \& STURT, P. (2002). Depth of processing in language comprehension: Not noticing the evidence. Trends in Cognitive Sciences, 6, 382-386.

SiMONS, D. J., \& LEVIN, D. T. (1997). Change blindness. Trends in Cognitive Sciences, 1, 261-267.

\section{NOTE}

1. Also, the critical word was an argument in Experiment 1 and a modifier in Experiment 2.

(Manuscript received February 26, 2003; revision accepted for publication October 13, 2003.) 